\title{
EFFECTS OF ORGANIZATIONAL FACTORS ON INTERNAL-ENTREPRENEURSHIP: CASE OF 5-STAR HOTELS IN NORTH CYPRUS
}

\author{
DOI: $10.17261 /$ Pressacademia.2020.1268 \\ PAP- V.11-2020(40)-p.206-210
}

\section{Mete Girgen}

International Final University, Tourism and Hospitality Department, Girne, Northern Cyprus. mete.girgen@final.edu.tr, ORCID: 0000-0003-2709-5639

\section{To cite this document}

Girgen, M., (2020). Effects of organizational factors on internal-entrepreneurship: case of 5-star hotels in North Cyprus. PressAcademia Procedia (PAP), V.11, p. 206-210

Permanent link to this document: http://doi.org/10.17261/Pressacademia.2020.1268

Copyright: Published by PressAcademia and limited licensed re-use rights only.

\begin{abstract}
Purpose- The main purpose of this research is to show how important organizational factors are in internal entrepreneurship for hotel businesses in Northern Cyprus. It is also one of the aims of this study to show the importance of these factors for businesse s in a competitive environment. Another aim is to define the independent and dependent variables of the research one by one.

Methodology- Independent variables are; organizational factors such as satisfaction, communication, power distance, rewarding and education. Dependent variables of the research is internal-entrepreneurship (creativity, innovation and proactivity). One of the data collection methods in the research is a method based on the literature research and another methods are surveys prepared for hotel employees and managers. SPSS (version 23) was used to analyze the data obtained.

Findings- The main ideas for the ten questions asked to the staff are as follows; organizational factors (satisfaction, communication, power distance, rewarding and education) have positive effects on internal entrepreneurship (creativity, innovation and proactivity). The government should rearrange entrepreneurship rules and regulations and encourage employees to be more creative in their work communication and job satisfaction play a very important role as institutional factors in the development of internal entrepreneurship; the HRM department should pay attention to these two important factors, both of which create productivity and productivity.

Conclusion- The interaction between communication, job satisfaction and performance is remarkable. As a conclusion, this study shows that there is a significant relationship between these two variables.
\end{abstract}

Keywords: Organizational factors, internal-entrepreneurship, HRM, tourism, North Cyprus.

JEL Codes: L83, L26, F20

\section{ÖRGÜTSEL FAKTÖRLERIN IÇ-GiRIşiMCiLiĞE ETKILERi: KUZEY KIBRIS'TAKI 5 YILDIZLIOTELIŞLETMELERi ÜZERINDE BIR ÇALIŞMA}

\section{ÖZET}

Amaç- Bu araştırmanın temel amacı, Kuzey Kıbrıs'ta bulunan otel işletmeler için, iç-girişimcilikte örgütsel faktörlerin ne kadar önemli olduğu göstermektir. Bu faktörlerin, rekabet ortamındaki işletmeler açısından önemini göstermek de bu çalışmanın amaçlarından biridir. Diğer bir amaç da araştırmanın bağımsız ve bağımlı değişkenlerini tek tek tanımlamaktır.

Yöntem- Bağımsız değişkenler; memnuniyet, iletişim, güç mesafesi, ödüllendirme ve eğitim gibi örgütsel faktörler olup, araştırmanın bağımlı değişkeni ise; iç-girişimciliktir (yaratıcılık, yenilikçilik ve proaktiflik). Veri toplama yöntemlerinden biri, literatür araştırmasına dayanan veri toplama yöntemi, diğerleri ise otel çalışanları ve yöneticiler için yapılan anketlerdir. Elde edilen verilerin analiz edilmesi için SPSS (sürüm 23) kullanılmıştır.

Bulgular- Personellere sorulan on soruya ait ana fikirler şu şekildedir: Örgütsel faktörlerin (memnuniyet, iletişim, güç mesafesi, ödüllendirme ve eğitim) iç-girişimcilik (yaratıcılık, yenilikçilik ve proaktiflik) üzerinde olumlu etkileri vardır. Hükümet, girişimcilik kural ve düzenlemelerini yeniden düzenlemeli ve çalışanları işlerinde daha yaratıcı olmaya teşvik etmelidir. İletişim ve iş tatmini, iç girişimciliğin geliştirilmesinde kurumsal faktörler olarak çok önemli bir rol oynamaktadır. İY departmanı bu iki önemli faktöre dikkat etmelidir, her ikisi de üretimde ve üretkenlik yaratır.

Sonuç- Yapılan araştırmada iletişim ve iş tatmini ile performans arasındaki etkileşim dikkat çekicidir. Bu iki değişken arasında son bir anlamlı ilişki olduğunu göstermektedir.

Anahtar Kelimeler: Örgütsel faktörler, iç-girişimcilik, IKY (İnsan Kaynakları Yönetimi), turizm, Kuzey Kıbrıs.

JEL Kodları: L83, L26, F20 


\section{GíRiş}

İç-girişimcilik kavramı, işletmelerde yeni fikirleri uygulanmak, yaratıcı çözümler ve kararlar üretilmek, risk almak ve yenilikçi olmak gibi temel uygulamaları içermektedir (Zahra ve Covin 1995). Bu araştırmanın temel amacı, Kuzey Kıbrıs'ta bulunan otel işletmeler için, iç-girişimcilikte örgütsel faktörlerin ne kadar önemli olduğu göstermektir. İşletmelerin örgüt kültürü ve bağlı oldukları değerleri geliştirmek için özel çaba sarf ederse, bu durum iş girişimciliği olumlu yönde destekleyecektir (Naktiyok ve Kök, 2006). Eğitim ve gelişim programları, çalışanların verimliliğini, yaratıcılığını ve iş yerindeki yenilikçiliği artıracaktır. Bu araştırma, örgütsel faktörlerin iç-girişimcilik üzerindeki etkilerini açıklamaya çalışacaktır. Kuzey Kıbrıs'ta örgütsel faktörlerin iç-girişimcilik üzerindeki etkilerini gösteren çok fazla araştırma yapılmaması araştırmayı daha önemli bir hale getirmektedir (Lo ve diğerleri, 2010). Bu, örgütsel faktörlerin gelişmemiş olduğu ve kısa vadede Kuzey Kıbrıs'taki turizm sektörünü olumsuz etkilemediği görülmektedir. Uzun vadede bu durum bir soruna dönüşebilir. Bunun sebebi, günümüzde teknolojinin gelişmesi ve gelişen teknoloji ile herşeyin daha kolay ulaşılır hale gelmesidir (Ağca ve Kurt, 2007). Girişimcilik, bir bireyin veya bireyler grubunun eylemleriyle yeni ekonomik, sosyal, kurumsal ve kültürel ortamlar yaratma çabaları olarak da adlandırılmaktadır (Deakins ve Freel, 2009). Çalışma örgütsel faktörlerin buna bağlı olarak hoşgörülü davranış vb. davranışların, çalışanları iş ortamında daha yenilikçi olmaya ittiği, biraz riskli fakat proaktif bir yaklaşım olduğu görülmüştür. Potansiyel girişimciler yaratmak için riskleri almak ve onları başarıya çevirmek gereklidir. Yeni davranışsal arketipler iç-girişimciliği artırabilir. Yüksek kaliteli işletmeler, uygun kaynak yönetimi yoluyla toplumun refahı artırmaktadır. Esas olarak bu kuruluşların büyüklüğü ve heterojenliği nedeniyle yenilikçi ve girişimci çözümler ortaya çıkmaktadır (Karyotakis ve diğerleri, 2015). Eğer organizasyon içi herhangi bir gelişmiş kültürel faktör yoksa, eğitim ve öğretim programları hiçbir şey ifade etmemektedir (Naktiyok, 2004). Herhangi bir işletmeye bağlı organizasyanel kültür içeriğinde bulunan organizasyon normları, etik ve ağlaki değerler sürekli geliştirilmelidir. Tüm işletmeler, kendine ait organizasyonel kültürü belirlerken belli kurallara ve devletin öngördüğü yasalara uymalıdır. İşletmeler personelleri için eğitim ve gelişim programları hazırlamalı, kariyerlerini geliştirmeli ve onları güvence altına almalıdır (Foley, 2013). Profesyonellik terimi, Kuzey Kıbrıs'taki iş terminolojisine girmelidir. İç-girişimcilik konusundaki eğitimler ise, personellerin yeni fikirlere açık olma ve yeni fikirler üretip onların geliştirilmesinde, yöneticiler ile birlikte uyum içerisinde çalışmalar üretmekte fayda sağlayacaktır (Yiğit, 2014). Organizasyonel faktörleri geliştirmek için Kuzey Kıbrıs'ta bulunan işletmelerin IKY departmanlar ını iyileştirmeleri gerekmektedir. Bu çalışma, otelcilik işletmeleri iç-girişimcilikte örgütsel faktörlerin önemini göstermeyi ve turizm sektörü için ne kadar önemli olduğunu araştırmayı amaçlamıştır. Diğer bir amaç da araştırmanın bağımsız ve bağımlı değişkenlerini tek tek tanımlamaktır. İşletmeler örgüt kültürü değerlerini geliştirmek için ne kadar çaba sarf ederse, bu aynı ölçüde iç-girişimciliği olumlu yönde etkileyecek ve çalışanların verimliliğini, yaratıcılı̆ını ve yenilikçiliğini artıracaktır (Uittenbogaard ve diğerleri, 2005). Çalışanların iç-girişimcilik davranışını etkileyen bireysel, örgütsel ve çevresel faktörler önem kazanmaktadır (İ̧̧can, 2006).

\section{LITERATÜRTARAMASI}

İş kollarını genişletmek ve artan rekabet ortamında rakip işletmelerle yarışmak işletmeler için hiçbir zaman kolay olmamıştır. Ancak girişimcilikte örgütsel bir dönüşüm sağlamak için girişimcilik davranışlarının örgüt içindeki belli departmanlar tarafından benimsenmesi gerekmektedir. Bu departmanların başında IKY gelmektedir (Parry ve Sinha, 2005; McBeth ve Rimac, 2004). Bu noktada, yöneticilere ek olarak, iç-girişimcilik işletme içindeki tüm meslekleri ve bakış açılarını kapsamalıdır. Bu nedenle farklı mesleklerin girişimcilik eğilimleri ile ilişkisi noktasında örgütsel faktörlerin araştırılmasına ve geliştirilmesine işletmeler tarafından ihtiyaç duyulduğu aşikardır (Goosen ve diğerleri, 2002). İç girişimciliğin finansal performans üzerindeki etkilerini belirlemeye yönelik bazı çalışmalar bulunmaktadır, çalışma ortamındaki iş memnuniyeti, iletişim ve güç mesafesi gibi finansal olmayan davranışsal değişkenlerle ilişkili olarak çok sınırlı araştırmalar bulunmaktadır (Akdoğan ve Cingöz, 2008). Bu nedenle, iç-girişimciler üzerindeki çalışmalar birçok bireysel ve örgütsel faktörü etkilemektedir. En çok bilinen ve çalışılan tutumlardan biri olan iş tatmininin, örgütsel faktörler - iç-girişimcilik etkileşiminin aracılık etkisine çok fazla odaklanmadığı söylenebilir (Dess ve Lumpkin, 2005). Çalışmanın temel amacı, ödül sistemi, örgütsel yapı, örgütsel iletişim ve iş tatmini gibi faktörlerin içgirişimciliğin davranışları üzerindeki etkilerini incelemektedir. Ayrıca, örgütsel faktörlerin iç-girişimcilik ve iş tatmini üzerindeki etkilerini araştırmak (De Villiers, 2008).

\section{1. Örgütsel Faktörler}

Bu araştırma IKY yöneticileri tarafından uygulanan ve iş tatmini, iletişim, ekip üyeleri arasındaki güç mesafesi, organizasyonların ücret ve ödüllendirme sistemleri ile oryantasyon faaliyetlerini içeren organizasyonel faktörleri tanımlamaya çalışacaktır (Corbett ve diğerleri, 2007). Bu örgütsel faktörler doğru uygularlarsa çalışanların verimliliğini, yaratııılığını ve yenilikçiliğini artıracaklardır. Öte y andan örgütsel faktörler bazı sosyo-kültürel değerleri, gelenekleri, inançları ve herhangi bir şirketin disiplin düzeyi, kuralları ve yönetmelikleri gibi diğer önemli değerleri içerebilir (Fiş, 2009). Bunlar, işletme kuruluşlarındaki sahibin, yöneticilerin ve çalışanların beklentilerini içer ir. Organizasyonel kültürel değerleri açıklamanın en basit yolu olan şirketlerin normları, gelenekleri ve kültürel faktörleridir.

İş Memnuniyeti: Çalışanlar bir işletmenin en önemli kaynağıdır. Çalışanları mutlu etmek, bir işletmeye pek çok avantaj sağlar. Çalışan iş bırakma oranı düşer. İKY departmanına atfedilen en yüksek maliyetlerden biri olabilir (Wiklund ve Shepherd, 2005).

Etkili İletişim ve Güç Mesafesi: Çalışanlar ve yöneticiler arasındaki iletişim ve güç mesafesi çok önemlidir. İşyerinde etkili iletişim bir işletmenin başarısının ayrılmaz bir parçasıdır; şirket içinde ve müşterilerle ilişkileri geliştirir ve çalışan katılımını ve bir ekibin genel etkinliğini artırır (Thornberry, 2003). İş başında iletişim ve iş tatmini ile performans arasındaki etkileşimi dikkat çekicidir ve bu iki değişken arasında son bir anlamlı ilişki olduğunu göstermektedir (Zara ve Garvis, 2000).

Ödüllendirme: İş insanlarını motive etmek, işletmelerin verimliliğini artırmak ve yeniliği artırmak için kullanılan en etkili araçlardan biri ödül sistemidir. Örgütsel stratejilerle ilişkili ücret ve ödüllerin örgütsel performans üzerinde daha etkili olduğu bilinmektedir. İKY departmanı, çalışanların organizasyondaki çalışanların yaratıcı, proaktif ve uygun maliyetli olmasının yanı sıra iç-girişimcilik davranışının sağlanması için doğru tasarlanmış ödül sistemi konusunda rehberlik etmektedir. Hough ve Scheepers'ı (2008) araştırmalarına göre işletmeler çalışanlara ne 
kadar çok ödül verirse, çalışanların o kadar yenilikçi olacaktır. Buna ek olarak, Ahmad ve ark., (2012) yaptıkları araştırmada ödül sisteminin kurumsal girişimcilik üzerinde önemli bir olumlu etkisi vardır.

Eğitim Programları: Tüm işletmeler için oryantasyon ve eğitim programlarıçok büyük bir önem taşımaktadır. Oryantasyonun tanımı İK departmanı tarafından bir kişiyi bir işin belirli noktalarına yönlendirmek için yapılan faaliyetler olabilir (Wang, 2008). Bu çalışmada, eğitimin önemi ve iç-girişimciliğin etkinliği değerlendirilmiştir (Kuratko, 2003). Kurumsal girişimcilik temelde büyük bir şirkette geliştirilen yeni idealler ve fırsatlardır. Sonuçta, idealin tamamı inovasyon etrafında dönmektedir. Bu süreç, herhangi bir şirkete rakipleri üzerinde rekabet avantajı sağlayabilir, ancak bu, ilgili risklerin olmadığı anlamına gelmez (Karabey ve Bingöl, 2010). Bu durumda, çalışanların verimliliğini ve performansını artırmak için eğitim programları oluşturulmalıdır. İşletmeler iKY bünyesinde girişimcilik eğitim programları kurmalıdır. Bu programlar işletme çalışanlara büyük fayda sağlayabilir. Çalışanların programlarla birlikte, aidiyet hissiy atları artacak, bu onların iş bırakma oranı düşürecek, üretkenliğini ve performansını artıracak ve şirketin bir parçası olduklarını hissettirecektir (Morris ve Kur atko, 2002). Bir şirketin iki tür çalışanı vardır: düzenli çalışanlar ve daha sonra fantastik idealler yaratmak için maaş alan çalışanlar. Büyük idealleri olan düzenli bir çalışan kendi ideallerini söyleyebilir ve bu ideallerin bir kısmının gerçeğe dönüşmesi mümkündür. Çalışanlar yeterince para kazanma idealleri üretebilirse, promosyon almaları muhtemeldir. Daha iyi bir ödeme pozisyonu için rekabet etmeye çalışan çalışanlarla dolu bir işletme kesinlikle büyük para kazanabilecek ve bazı büyük yenilikçi fikir ve idealler yaratacaktır (Hough ve Screepers, 2008). Sonunda, bu, çalışanların genel moralini artıracak ve daha sıkı çalışmalarını sağlayacaktır. Kısacası, çalışanlar iç-girişimcilik ile ilgili yeterli eğitimleri almalıdır. Bu eğitimler, benimsenen yeni fikir ve uygulamaların, sürekli olarak aynı kararlılıkla uygulanmasını, sürdürülebilirlik, ye terlilik ve verim açısından önemlidir (Schenieder, 2017).

\section{2. İç-Girişimcilik}

Girişimcilik, bireylerin veya kuruluşların fırsatlarını tanıma ve sürdürme süreci olarak görülebilir. Girişimci davranış, risk almak ve zorluklarla karşı karşıya gelme ve stratejik vizyonun öngörülme şeklini etkilediği için bir organizasyona yaratıcılık ve çözüm üretme konularında değer katar ve yönelim değişikliği ile organizasyon içi karakterinde daha enerjik bir ortam oluşturur (Wu, 2011). İç-girişimcilik kavramı ise, yeni fikirleri ve geliştirme faaliyetlerini arttırdığı için herhangi bir işletme organizasyonu için çok önemlidir. Bu faaliyetler örgütsel faktörler, kültür kurumsal girişimcilik ve girişimcilik gibi bazı terimleri içerir ve bu terimler kurumsal girişimciliğ in örgütsel kültürel kavramları olarak kullanımıştır (Zahra ve Garvis, 2000). Günümüz rekabet ortamında, girişimci olan işletmeler, farklı fikir ve yeniliklerle diğer işletmelerle girdikleri rekabette avantaj sağlama amacındadır (Sebora ve diğerleri, 2010; Mokaya, 2012). İç-girişimcilik yeniliğe dayanmaktadır, onu geliştiren kuruluş için sürekli avantaj sağlayan yeni bir teknoloji, ürün kategorisi veya iş modeli anlamına gelmektedir (Rutherford ve Holt, 2007). Başarılı ticarileştirmeler ile, organizasyon için yeni bir büyüme hızı kaynağı oluşturmaktadır. Uzun vadede, artan iyileştirmeler ve takip eden yeniliklerle gelirlerin sürekliliği için bir fırsat sunmaktadır. Bu nedenle, kurumsal girişimcilik yeni bir üründen veya bir kerelik piyasa tanıtımından çok daha fazlasıdır. Bir şirket için ayrı bir rekabetçi pozisyona ve firmanın müşterileri için istisnai değere dayanan sürdürülebilir yeni bir iş yaratmayı hedeflemektedir (Papatya, 2005). Gerçek kurumsal girişimcilik insanlara dayanır. Bu işletmeleri geliştiren girişimciler ve onlara rehberlik eden ve onları destekleyen yöneticilerden oluşan bir ekip çalışmasıdır (Kelley, 2011). Bu kavram, şirketin uygulamalarında farklı karar ve yöntemler üretmek, risk almak ve yenilikçi olmak gibi uygulamaları içermektedir. Diğer işletmelerle rekabet edebilmek için örgütsel kültür benimsenmelidir. İşletme içi belirlenen uygulamalara bireyler uyum sağlayamazsa iç-girişimcilik sağlanamaz, yani bireysel faktörler de çok önemlidir (Bulut ve Yılmaz, 2008).

\section{3. Örgütsel Faktörlerin İç-Girişimciliğe Etkileri}

İç girişimcilik, kurulmuş şirketler düzeyindeki girişimcilik faaliyetlerini de içermekte olup, işletme organizasyonlarında ek onomik büyüme ve performansa yol açan organizasyonel verimlilik, verimlilik, etkinlik, kârlılıkta önemli bir unsur olarak kabul edilmiştir. Bazı araştırmalar, kurumsal iç faktörlerin kurumsal girişimcilik üzerinde olumlu etkileri olduğunu göstermektedir. Antoncic ve Hisrich, (2004) çalışmalarının sonucunda, iç-girişimcilik davranışlarının, inovasyon, proaktif ve risk alma, örgütsel performansla olumlu ilişkili olduğunu göstermektedir. Organizasyonel faktörler örgüt kültürünü oluşturan en temel faktörlerdir (Kocabakcak, 2006). Bu faktörlerin birçoğunun bilinçaltında olduğu ve tutumlar, davranışlar, duygular, ilişkiler, dil, fiziksel ortamlar, sembolizmler ve eserler aracılığıyla ifade edilebildiği her seviyedeki çalışanların özelliklerini, değerlerini ve inançlarını içerdiği söylenebilir. Bu anlamda çok farklı görüşler ortaya çıkar ve fikir zenginliği oluşur. Örgütsel faktörler, çalışmada iyi iletişim ve mutlu çalışma ortamının kaliteli bir eğitimle birleştiğinde girişimcilik üzerinde olumlu olduğunu göstermektedir. Temel bileşenleri olan paylaşılan değerler, inançlar ve beklenen davranışlar, ya sosyalleşme süre cinde ya da temel değerler, varsayımlar ve inançlar yoluyla inovasyon üzerinde etkili olabilir. Organizasyonel kültür ise, politikalar, yapılar, prosedür ler ve süreçler yoluyla yaratıcılı̆ı ve yeniliği etkilediği için organizasyonel inovasyon için hayati öneme sahiptir (Dobni, 2008).

\section{ARAŞTIRMA YÖNTEMLERI}

Araştırmada ilk method olarak literatür araştırmasına dayanan veri toplama yöntemi kullanılmıştır. Bu araştırmada iç-girişimciliği (yaratıcılık, yenilikçilik, proaktiflik) olumlu yönde etkileyen beş özel organizasyon faktörü (memnuniyet, etkili iletişim, ödüllendirme, yönlendirme ve güç mesafesi) araştırılmış ve araştırma modelinde gösterilmiştir. Çalışmada karma yöntemler kullanılmış olup, mülakat ve yazılı soruları içermektedir. Birincil veri toplama aracı olarak ise çalışmada biri demografik bilgi toplamak, biri çalışanlar için ve diğeri yöneticiler için olmak üzere üç adet anket kullanılmıştır. Hedef kitle, Kuzey Kıbrıs'taki 5 Yıldızı Otel İşletmelerinde görevli yöneticiler ve personellerdi. Veriler, tamamen iş ortamında gerçekleştirilen bir anket kullanılarak toplanmıştır. Anketler otellerde 100 çalışan ve 20 departman yöneticisine dağıtılmıştır. Çalışanlardan alınacak cevaplarda aracı olarak, yanıtlayııının cevabı birkaç seçenekle sınırlı olacak ş ekilde cevapladığı kapalı uçlu anketler kullanılmıştır. 


\section{SONUÇ}

Oteldeki IKY departmanı, eğitim programlarını tasarlarken dikkatli olmalıdır. Araştırmaya seçilen katılımcıların cevapları ge nellikle benzer olmuştur. Personellere sorulan on soruya ait ana fikirler şu şekildedir: Örgütselfaktörlerin (Memnuniyet, İletişim, Güç mesafesi, Ödüllendirme ve Eğitim) İç-Girişimciliktir (Yaratıcılık, Yenilikçilik ve Proaktiflik) üzerinde olumlu etkileri vardır. Oluşturulan eğitim tüm eğitim ve oryantasyon programları, çalışanların yaratııılığını, yenilikçiliğini ve proaktifliğini artırmak için oluşturulmalıdır. Güçlü bir insan kaynakları yönetimi, esnekliği, inisiyatifleri, özerkliği ve özgürlüğü teşvik eder ve bilgi yönetimine odaklanarak doğrudan ve yenilikçi çözümler bulmanın yanı sıra bir ekip üyesinin gelişimine odaklanır. Bu girişimci bir organizasyon kültürünün geliştirilmesi ve bu bilinçle beslenmesini esas kılar. Turizm sektör çalışanları böyle bir kültür ve eğitim ile kariyerleri için hedef belirleyebilirler. Bu da, onların geleceğe umutla ba kması, iş yerlerinde daha mutlu çalışması gibi olumlu etkilerle sonuçlanmaktadır. Risk alan ve yenilikçi personeller kısa sürede basit hatalar yapabilir, zaten risk almak da bunu gerektirmektedir. Fakat iyi bir iletişimin olduğu, mutlu bir çalışma ortamında çalışanlar mükemmel bir şekilde üretken olacaklardır. İşletmelerin girişimcilik kültürü, onları yenilikçi ve riske dayanıklı olmaya iter. Bu tür davranışlar örgütsel öğrenmeyi geliştirerek araştırma ve deneylerle sonuçlanır (Karyotakis ve Moustakis, 2015). Girişimcilik faaliyetlerinden yararlanmak için bir kuruluşun öğrenme taahhüdü, değişime karşı açık görüşlülük ve paylaşılan vizyona uygun ilkeler tarafından yönetilmesi gerekir. Çağdaş dinamik ve değişken koşullar, yaratıcılığı, üretimi, yeni fikirleri, yeniliği, proaktif davranışı, risk alma ve rasyonel yönetimi, ödüllendirmeyi ve yetiştirme olgunluğunu, değişime hazırlığı ve açık fikirliliği teşvik edecek çalışma ortamını savunmaktadır. Bütün bunlar sadece uyum ve gelişme için değil, aynı zamanda uygulanabilirlik nedeniyle de tüm organizasyonlar için çok önemli ve değerlidir. Katılımcıların görüşleri temel olarak organizasyonel faktörlerin iç-girişimciliğe olumlu etkileri olduğunu göstermektedir ki literatür taraması da bunu güçlü bir şekilde kanıtlamaktadır. Bu faktörleri sağlayamayan işletmeler başarısız olmaya mahkumdur. Özellike günümüzde yaratıcı fikirler, özgür ruhlu insanlar tarafından mutlu bir çalışma ortamında ortaya çıkmaktadır. İşletmelerdeki iç-girişimciliğinin ana personel profilleri yöneticiler, insan kaynakları departmanı çalışanları ve verdikleri eğitimleri alan çalışanlardır. Bu kişiler iç girişimciliğin ana profilleridir. İnsan Kaynaklar personeli, çalışmada gösterildiği üzere eğitimler, mutlu bir çalışma ortamı yaratma konusunda, etkili iletişim ve en önemlisi güçlü bir organizasyon kültürü oluşturmalı, başarılı çalışanları ödüllendirmelidir.

\section{REFERENCES}

Ağca, V. ve Kurt, M. (2007). İ̧̧ Girişimcilik ve Temel Belirleyicileri: Kavramsal Bir Çerçeve, Erciyes Üniv. I.i. B.F. Dergisi, 29, 83-112.

Ahmad, N.H., Nasurdin, A.M., \& Zainal, S.R.M., (2012), Nurturing Intrapreneurship to Enhance Job Performance: The Role of ProIntrapreneurship Organizational Architecture, Journal of Innovation Management in Small \& Medium Enterprises, Vol. 2012, Article ID 868880, 9 pages, http://www.ibimapublishing.com/journals/JIMSME/jimsme.html

Antoncic, B. and Hisrich, R.D. (2004), Corporate entrepreneurship contingencies and organizational wealth creation, Journal of Management Development, Vol. 23 No. 6, pp. 518-50.

Bulut, C. \& Yilmaz, C., (2008), Innovative Performance Impacts of Corporate Entrepreneurship: An Empirical Research in Turkey, Proceedings of Academy of Innovation and Entrepreneurship Conference, pp. 414-417, Beijing, China.

Corbett, A.C., Neck, H.M. \& DeTienne, D.R. (2007). How corporate entrepreneurs learn from fledgling innovation initiatives: Cognition and the development of a termination script. Entrepreneurship Theory and Practice, 31(6):829-852.

De Villiers, I. (2008). An assessment of corporate entrepreneurship in the South African Broadcasting Corporation limited (SABC). (Unpublished MBA-dissertation.) North-West University, Potchefstroom

Deakins, D and Freel, M. (2009). Entrepreneurship and small firms. 5th Edition. New York: McGraw Hill, 2009.

Dess, G.G., \& Lumpkin, G.T. (2005). The role of entrepreneurial orientation in stimulating effective corporate entrepreneurship. Academy of Management Executive, 19(1):147-156.

Dobni, C.B. (2008). Measuring innovation culture in organizations: The development of a generalized innovation culture construct using exploratory factor analysis. European Journal of Innovation Management, 11(4), 539-559. doi:10.1108/14601060810911156.

Fiş, M.A. (2009), Unlocking The Relationship Between Corporate Entrepreneurship and Performance, İstanbul: Sabancı Üniversitesi Sosyal Bilimler Enstitisü, Yayınlanmamış Doktora Tezi.

Foley, S. (2013). 5 reasons why intrapreneurship is important, Erişim tarihi: 29 Ocak 2016, http://www.corporateentrepreneurs.com/2013/11/08/5-reasonswhy-intrapreneurship-is-important/

Goosen, C.J., De Coning, T.J. \& Smit, E. v.d.M. (2002). Corporate entrepreneurship and financial performance: The role of management. South African Journal of Business Management, 33(4):21-27.

Hough, J. \& Screepers, R., (2008), Creating Corporate Entrepreneurship through Strategic Leadership, Journal of Global Strategic Management, vol 3.

İşcan, Ö. F. (2006). Dönüştürücü/etkileşimci liderlik algısı ve örgütsel özdeşleşme ilişkisinde bireysel farklııkların rolü. Akdeniz Üniversitesi iktisadi ve Idari Bilimler Fakültesi Dergisi, 11, 160-177. 
Karabey, C. N., ve Bingöl, D. (2010). Girişimciliğin başlangııı olarak fırsat tanımlama. İstanbul Üniversitesi işsletme Fakültesi Iş̧letme iktisadı Enstitüsü Dergisi: Yönetim, 67. 9-31.

Karyotakis, K.M., \& Moustakis, V.S. (2015). Innovating in Public Administration. Paper presented at the 12th Student Conference of Science and Technology, Athens University of Economics and Business \& Hellenic Management Association, Athens, 14 May (pp. 114-124). In Greek.

Karyotakis, K.M., Bakatsaki, M., \& Moustakis, V.S. (2015). The Entrepreneurial Facets Of Public Administration. Paper presented at the Synthesis International Scientific Conference of IT and Business- Related Research, Singidunum University, Belgrade, 16-17 April (pp. 327331). doi:10.15308/Synthesis-2015-327-331.

Kelley, D. (2011). Sustainable corporate entrepreneurship: Evolving and connecting with the organization. Business Horizons, 54, 73-83. doi:10.1016/j.bushor.2010.09.003

Kuratko, D. F. (2003). Entrepreneurship education: emerging trends and challenges for the 21st century. Coleman Foundation White Paper Series for the U.S. Association of Small Business \& Entrepreneurship.

Lo, M. C., Ramayah, T., Min, H. W., ve Songan, P. (2010). The relationship between leadership styles and organizational commitment in Malaysia: role of leader-member exchange. Asia Pacific business review, 16, 79-103.

McBeth, E.W. \& Rimac, T. (2004). The age of entrepreneurial turbulence: creating sustainable advantage for individuals, organizations, and societies in the new century. ESADE MBA Business Review, 2:17-23.

Mokaya, S.O., (2012), Corporate Entrepreneurship and Organizational Performance Theoretical Perspectives, Approaches and Outcomes, International Journal of Arts and Commerce, Vol. 1 No. 4.

Morris, M. H. ve Kuratko, D. F.; (2002), Corporate Entrepreneurship: Entrepreneurial Development within Organizations, Harcourt College Publishers, Orlando, Florida.

Naktiyok, A., ve Kök, B. S. “Çevresel Faktörlerin İç Girisimcilik Üzerine Etkileri, Afyon Kocatepe Üniversitesi, i.i. B.F. Dergisi, 8:2, 2006, 78-96.

Papatya, N. (2005), Sürdürülebilir Başarı için İç-Girişimcilik, İstanbul: Hayat Yayıncılık No. 210/59, 83-87.

Parry, W. K., ve Sinha, N. P. (2005). Researching the Trainability of Transformational Organizational Leadership, Human Resource Development International, 8, 165-183.

Rutherford, W.R., \& Holt, D.T., (2007), 'Corporate Entrepreneurship: An Empirical Look at the Innovativeness Dimension and Its Antecedents', Journal of Organizational Change Management, Vol. 20 No. 3, pp. 429-446.

Schneider, K. (2017). Promoting the Entrepreneurial Success of Women Entrepreneurs Through Education and Training. Science Journal of Education. Vol. 5, No. 2, , pp. 50-59. doi: 10.11648/j.sjedu.20170502.13.

Sebora, T.C., Theerapatvong, T. \& Lee, S.M., (2010), 'Corporate entrepreneurship in the face of changing competition: a case analysis of six Thai manufacturing firms', Journal of Organizational Change, Vol. 23 No. 4, pp. 453-70.

Thornberry, N. (2003), Corporate Entrepreneurship: Teaching Managers to be Entrepreneurs, The Journal of Management Development, 22(4), 329-344.

Uittenbogaard, B., Broens, L. \& Groen, A.J. 2005. Towards a guideline for design of a corporate entrepreneurship function for business development in medium-sized technologybased companies. Creativity and innovation management, 14(3):258-271.

Wang, C. L., (2008), Entrepreneurial orientation, learning orientation, and firm performance. Entrepreneurship Theory and Practice, 32(4): 635-656.

Wiklund, J., and Shepherd, D.; (2005). Entrepreneurial Orientation and Small Business Performance: A Configurational Approach, Journal of Business Venturing, 20 (1), ss. 71-91.

Wu, J. (2011). Asymmetric roles of business ties and political ties in product innovation. Journal of Business Research, 64(11), 1151-1156. doi:10.1016/j.jbusres.2011.06.014.

Yiğit, S. (2014). İnovasyona davranışsal yaklaşımın bir yansıması: Kurumsal Gir işimcilik, International Journal of Social Science, 30, 411-428.

Zahra, S. \& Covin, J.G., (1995). Contextual Influences on The Corporate Entrepreneurship-Performance Relationship: A Longitudinal Analysis, Journal of Business Venturing, 10, 1995, 44.

Zahra, S., D. Garvis (2000), International Corporate Entrepreneurship and Firm Performance: The Moderating Effect of International Environmental Hostility, Journal of Business Venturing, 15(5), 469-492. 